\title{
Nutraceutical potential of selected spices, vegetables used as animal feed, and agri-food wastes
}

\begin{abstract}
Due to their health effects, the consumption of vegetables, fruits, and spices has been encouraged for a long time. The compounds responsible for the health benefits of these foods are products of the secondary metabolism in plants known for their ability to prevent or remove free radicals and repair oxidative damage. These active biomolecules are distributed in both edible and inedible parts of foods and in spices. The aim of this research was to evaluate phenolic concentrations and antioxidant activity of 3 spices native of the Far East (wasabi, ginger, and turmeric), one spice native of the East Europe (horseradish), two vegetables used in animal feeds (carobs and horse beans), and three agro-industrial wastes (pistachio hulls, pomegranate peels, and tomato stems). The phenolic fractions were extracted using water as solvent. The highest phenolic concentrations and antioxidant activity were detected in pomegranate peels. Traditional spices, horse beans and tomato stems had the lowest antioxidant contents.
\end{abstract}

Keywords: antioxidant, hulls, nutraceutic, phenolic, spice, waste
Volume 6 Issue 4 - 2018

Antonietta Baiano, Maria Assunta Previtali
Dipartimento di Scienze Agrarie, University of Foggia, Italy

Correspondence: Antonietta Baiano, Dipartimento di Scienze Agrarie, degli Alimenti e dell'Ambiente, University of Foggia, Via Napoli, 25-7| I 22 Foggia, Italy, Tel +39 88I 589249,

Email antonietta.baiano@unifg.it

Received: June 29, 2018 | Published: July 26, 2018

\section{Introduction}

Although the consumption of certain foods for their healthpromoting effects is a practice diffused for centuries, the interest in bioactive food components is always growing. 'Dietary phytochemicals such as polyphenols, glucosinolates, phytoestrogens, terpens could have a role in the reduction of the incidence of degenerative or chronic diseases. ${ }^{2}$ These compounds are widely diffused in the vegetable kingdom, both in the edible parts of foods and in agro-industrial wastes. Thus, their intake can be obtained by diet or they can be recovered from the inedible food parts and then used in the food industry for obtaining functional food or in the pharmaceutical industry for the production of supplements.

Spices are parts (seeds, stems, leaves, roots) of plants, used whole or ground in order to enhance the sensory characteristics of foods and beverages. The compounds responsible for these properties such as terpenes and derivatives, phenylproponoids, isothiocyanates, sulfur compounds, are the same the made the spices useful in the traditional medicine for the treatment of various diseases. ${ }^{3,4}$ Most of the health benefits of spices depend on their antioxidant ability. ${ }^{5}$ Among the traditional spices, there is a growing interest for wasabi, horseradish, turmeric, and ginger whose antioxidant properties depend on allyl isothiocyanate, polyphenols, curcuminoids, and gingerols (shogaols, paradols, and zingerone) contents, respectively. ${ }^{6}$

Agro-industrial wastes consist in residual biomass produced by food industries as results of processing of fruit and vegetables. ${ }^{7}$ They can include leaves, seeds, roots, stems. In Europe, the food industry generates 250 million tons/year of by-products, waste and effluents and $6 \%$ of them is represented by fruits and vegetables. ${ }^{8}$ In addition to agro-industrial wastes, there are crops not involved in human consumption but cultivated within the so-called crop rotation, whose products are used in animal feed (horse or tic beans, for example). Further, there are crops whose parts generally have industrial use in food sector that generates a lot of waste (carobs, for example).

Wastes and by-products represent a loss of valuable biomass and nutrients and determine potentially pollution problems because of their high organic matter content. ${ }^{7}$ Furthermore, legislation reasons force the industry to find alternative uses for the residual matter. ${ }^{9}$ An effective alternative to strategies of valorisation such as production of compost, animal feed, and bioethanol is represented by the extraction of biopolymers that can find several application in different fields including, as an example, the production of food nutrients and additives. ${ }^{10}$

Vegetable residues are sources of potential phytochemicals such as phenolic compounds with antioxidants and anti-inflammatory activity that should be used in food, cosmetic and pharmaceutical industries. Often, by-products have been found to contain higher amounts of phenolics than the edible parts. For example, peels from apples, peaches, pears, and nectarines were reported to contain twice the amount of phenolics of the peeled fruits ${ }^{11,12}$ while pomegranate peels contain amounts of phenolics ten times higher than those of the pulp. ${ }^{13}$ In such conditions, and considering the high value products obtained, the recovery of phenolic compounds seems to be economically interesting. In addition, the extraction methodology must be environmental friendly, in order to avoid that the remedy is worse than the disease. ${ }^{14}$

The aim of this work was to give an overview of the antioxidant potential of some traditional spices, fruits and vegetables are generally used for animal feed but also suitable for humans, and agro-industrial wastes.

\section{Materials and methods}

\section{Vegetable materials}

The spices analysed included rizhomes of ginger (Zingiber officinale Roscoe, 1807), turmeric (Curcuma longa) L., horseradish (Armoracia rusticana L.), and wasabi (Wasabia japonica (Miq.) Matsum). The following vegetables used in animal feed were analysed: horse beans (Vicia faba L.), carobs (Ceratonia siliqua L.) The vegetables wastes included: pistachio ((Pistacia vera L.) hulls, pomegranate (Punica granatum) peels, and tomato (Lycopersicon esculentum L.) stems. Wasabi was imported from Japan. The other vegetable matrices were purchased or recovered on a local market. 


\section{Extraction of phenolic fractions from wastes}

Before extraction, the solid wastes were finely chopped (5-8mmsize) by a 30 s-treatment in a domestic cutter (Philips HR1396/55, Milano, Italy). The extractions were performed using water as a solvent and the extraction conditions are reported in Table 1. Carob pods and seeds were analysed separately since, in addition to the use of the whole fruit in animal nutrition, seeds are widely used in food industry as thickeners due to their polysaccharide content.

\section{Analysis of the total phenolic content}

The total phenolic compounds were determined according to the Folin-Ciocalteau method. ${ }^{20}$ Quantification was based on a standard curve built with aqueous solutions of gallic acid (ExtraSynthese, Genay, France) having known concentrations. The total phenolic content was expressed as milligrams of gallic acid equivalents per gram of material.

Table I Extraction conditions applied to the various vegetable matrices

\begin{tabular}{|c|c|c|c|c|}
\hline \multirow{2}{*}{ Vegetable matrices } & \multicolumn{4}{|l|}{ Extraction conditions } \\
\hline & Solid-to-water ratio & Temp- $\left({ }^{\circ} \mathrm{C}\right)$ & Time(min) & References \\
\hline \multicolumn{5}{|l|}{ Traditional Spices } \\
\hline Wasabi & $5 \mathrm{~g} / 10 \mathrm{ml}$ & Room temp. & 2 & Tsao et al. ${ }^{15}$ \\
\hline Ginger & $5 \mathrm{~g} / 10 \mathrm{ml}$ & Room temp. & 2 & Tsao et al. ${ }^{15}$ \\
\hline Turmeric & $5 \mathrm{~g} / 10 \mathrm{ml}$ & Room temp. & 2 & Tsao et al. ${ }^{15}$ \\
\hline Horseradish & $5 \mathrm{~g} / 10 \mathrm{ml}$ & Room temp. & 2 & Tsao et al. ${ }^{15}$ \\
\hline \multicolumn{5}{|c|}{ Vegetables used in animal feed } \\
\hline Carob pods & $3 \mathrm{~g} / 50 \mathrm{~mL}$ & 95 & 12 & Roseiro et al. ${ }^{16}$ \\
\hline Carob seeds & $3 \mathrm{~g} / 150 \mathrm{~mL}$ & 95 & 12 & Roseiro et al. ${ }^{16}$ \\
\hline Horse beans & $5 \mathrm{~g} / 50 \mathrm{~mL}$ & Room temp. & 15 & Orak et al. ${ }^{17}$ \\
\hline \multicolumn{5}{|l|}{ Vegetable wastes } \\
\hline \multirow{2}{*}{ Pistachio hulls } & $10 \mathrm{~g} / 50 \mathrm{~mL}$ & 25 & 180 & Garavand et al. ${ }^{18}$ \\
\hline & $10 \mathrm{~g} / 50 \mathrm{~mL}$ & 80 & 60 & ---------- \\
\hline Pomegranate peels & $\mathrm{lg} / 50 \mathrm{~mL}$ & 100 & I & Çam \& Ïçyer ${ }^{19}$ \\
\hline Tomato stems & $2 \mathrm{~g} / 20 \mathrm{~mL}$ & 70 & 15 & Orak et al. ${ }^{17}$ \\
\hline
\end{tabular}

\section{Evaluation of the antioxidant activity}

The antioxidant activity of the phenolic extracts was evaluated on the basis of the scavenging activity of the ABTS (2,2'-azinobis(3ethylbenzothiazoline-6-sulfonic acid) diammonium salt) and DPPH (1,1-diphenyl 2-picrylhydrazyl free radical) stable radical, as described in Re et al., ${ }^{21}$ and Brand Williams et al., ${ }^{22}$ respectively. Data were expressed as mg trolox eq/g (ABTS) and mmol trolox eq/g (DPPH)

\section{Moisture analysis}

Moisture content was determined by placed the finely chopped vegetable material at $105^{\circ} \mathrm{C}$ until a constant weight was reached.

\section{Statistical analysis}

Each analysis was replicated at least three times. The averages and the standard deviations were calculated using Excel software V. 11.5.1 (Microsoft, Redmond, WA). The least significant difference (LSD) test $(p<0.05)$ and the one-way analysis of variance (ANOVA) were performed using the package Statistica for Windows V. 8.0 (Statsoft, Tulsa, OK).

\section{Results and discussion}

The total phenolic contents and antioxidant activity of spices, vegetables used in animal feed, and vegetable wastes referred to the dry matter are reported in Table 2. Obviously, the use of water as solvent reduced the extraction yield with respect to other solvents such as ethanol, methanol, acetone, but increased the process sustainability. Antioxidant activity detected by ABTS assay was significantly higher if compared to that by DPPH assay and, in agreement with the findings of other authors, ${ }^{23}$ these results suggest a greater effectiveness of ABTS assay in evaluating antioxidant capacity in a variety of foods.

The data highlighted the high correlation $(\mathrm{R}>0.99)$ obtained between phenolic content and antioxidant activity independently on the type of assay (ABTS or DPPH). This is an important result since the molecules responsible for the antioxidant power are quite different among the analysed vegetable matrices and the extraction method was not specific for phenolic compounds.

The matrices can be ideally grouped in three clusters due to their phenolic concentrations: high phenolic concentrations (pomegranate peels); medium phenolic concentrations (carob pods and seeds); low phenolic concentrations (horse beans, tomato stems, and all 
the spices). To further knowledge, the values of dry matter percent $(\%)$ are, in a decreasing order: horse beans $(94.9 \pm 0.3)$, tomato stems (92.9 \pm 0.2$)$, pistachio hulls $(92.8 \pm 0.1)$, carob seeds $(90.3 \pm 0.1)$, carob pods $(89.4 \pm 0.2)$, pomegranate peels $(86.9 \pm 0.1)$, horseradish (26.8 \pm 0.3$)$, turmeric $(22.3 \pm 0.4)$, wasabi (13.5 \pm 0.1$)$, ginger $(7.1 \pm 0.1)$.

Table 2 Total phenolic content (TPC) and antioxidant activity of the various vegetable matrices referred to dry matter

\begin{tabular}{|c|c|c|c|c|}
\hline \multirow{2}{*}{ Vegetable matrices } & \multirow{2}{*}{ TPC (mg gallic acid/g) } & \multicolumn{2}{|l|}{ Antioxidant activity } & \multirow{2}{*}{ Dry Matter (\%) } \\
\hline & & ABTS(mg trolox eq/g) & DPPH(mmol trolox eq/g) & \\
\hline \multicolumn{5}{|l|}{ Traditional Spices } \\
\hline Wasabi & $0.02 \mathrm{bA}$ & $8.07 \pm 1.85$ b C & $0.89 \pm 0.05$ b D & $13.5 \pm 0.1$ \\
\hline Ginger & $0.04 \mathrm{aA}$ & $24.93 \pm 4.50$ a $E$ & $1.69 \pm 0.14 \mathrm{a} \mathrm{E}$ & $7.1 \pm 0.1$ \\
\hline Turmeric & $0.01 \mathrm{cA}$ & $4.17 \pm 0.09 \mathrm{~d} \mathrm{~B}$ & $0.36 \pm 0.02 \mathrm{~d} \mathrm{~B}$ & $22.3 \pm 0.4$ \\
\hline Horseradish & $0.01 \mathrm{cA}$ & $7.17 \pm 1.84$ c C & $0.54 \pm 0.04$ c C & $26.8 \pm 0.3$ \\
\hline \multicolumn{5}{|c|}{ Vegetables used in animal feed } \\
\hline Carob pods & $16.13 \pm 0.50 \mathrm{~b} \mathrm{C}$ & $56.55 \pm 1.7 \mid$ a G & $9.96 \pm 0.52$ a G & $89.4 \pm 0.2$ \\
\hline Carob seeds & $18.64 \pm 0.28$ a $D$ & $47.17 \pm 2.24 \mathrm{~b} \mathrm{~F}$ & $5.5 \mathrm{I} \pm \mathrm{I} .18 \mathrm{~b} \mathrm{~F}$ & $90.3 \pm 0.1$ \\
\hline Horse beans & $0.01 \mathrm{cA}$ & $11.33 \pm 0.56$ c D & $0.35 \pm 0.17$ c A,C & $94.9 \pm 0.3$ \\
\hline \multicolumn{5}{|l|}{ Vegetable wastes } \\
\hline Pistachio hulls & $1.12 \pm 0.02$ b B & $2.02 \pm 0.03 \mathrm{cA}$ & $0.19 \pm 0.08 \mathrm{cA}$ & $92.8 \pm 0.1$ \\
\hline Pomegranate peels & $230.36 \pm 2.23$ a E & $933.36 \pm 25.52 \mathrm{a} \mathrm{H}$ & $318.7 \pm 110.48$ a H & 86.9 \\
\hline Tomato stems & $0.01 \mathrm{cA}$ & $3.97 \pm 0.76$ b B & $0.28 \pm 0.04 \mathrm{~b} \mathrm{~A}$ & $92.9 \pm 0.2$ \\
\hline
\end{tabular}

Within each category of vegetables, different letters indicate significant differences at $\mathrm{p}<0.05$ by LSD multiple range test.

The low phenolic concentrations of spices were quite surprising since the antioxidant contents of herbal/traditional plant medicine, spices and herbs were found higher than those of fruits and vegetables in the antioxidant food table made of 3139 products and elaborated by Carlsen et al. ${ }^{24}$ In my opinion, it is difficult to compare results obtained in specific conditions (origin, variety, extraction conditions) with reference values that are necessarily more generic. Spices are being used for several hundred years in India and other Countries of the Far East to treat a variety of diseases ${ }^{25}$ and, due to their low calories and relatively low prices, they have been considered suitable sources of antioxidants and other potential bioactive compounds in diet. ${ }^{26}$ To further reconsider the role of herbs and spices in antioxidant defense and redox signalling, the small amounts used for food aromatization must be taken into account. Nevertheless, to counterbalance this statement, phytochemical bioavailability and biological effects should be evaluate, since the most antioxidant foods are not necessarily those supplying the highest concentrations of active metabolites in target tissues. Differences in bioavailability are consequences of different absorption, transport, and metabolism, and eventually their effects on oxidative stress in various cellular compartments. Biochemically active phytochemicals could have biological properties that are not correlated with their antioxidant capacity. ${ }^{27}$

Low phenolic concentrations were found in tomato stems, according to a previous research of Silva-Beltrán et al., ${ }^{28}$ who highlighted higher phenolic concentrations in tomato leaves and higher chlorophyll concentrations in tomato stems. Nevertheless, tomato stems can be considered as a not negligible source of phenolics due to the large amount of industrial tomato produced in the worlds (about 38 milliontons in 2016) $)^{29}$ and the consequent high amount of leaves and stems available during the harvest period (95-98\% discarded while the remaining 2-5\% used as animal food). ${ }^{30}$ Also, although tomato leaves and stems have been considered potentially toxic because of the tomatine, this alkaloid is generally present in small concentrations and seems to be able to bind cholesterol molecules in the digestive system, thus lowering the levels of LDL cholesterol in humans and animals. ${ }^{30}$

Low phenolic concentrations were also detected in horse beans. These results are opposite to the finding of Boudjou et al., ${ }^{31}$ and Boukhanouf et al., ${ }^{32}$ who respectively extracted high phenolic amounts from horse bean hulls using aqueous $(70 \%)$ acetone and $(80 \%)$ ethanol and from immature fava bean fractions using $75 \%$ acetone. It is well known that the composition of the solvents significantly affects the measured phenolic content since solvent polarity increases phenolic solubility. Low phenolic contents were also detected in pistachio hulls in disagreement with the results obtained by Goly et al., ${ }^{33}$ who extracted phenolics from pistachio hulls using water as solvent. These different behaviours could be due to origin, variety, pedoclimatic conditions. Erşan et al. ${ }^{34}$ extracted 66 phenolic constituents from the non-lignified red and green pistachio hulls while Abbasi et al., ${ }^{35}$ stated the use of fermented dried pistachio hulls as possible functional food due to the increase of phenolic content during the first days of the SolidState Fermentation by the fungus Phanerochaete chrysosporium.

Carob pods and seeds had similar phenolic concentrations and should be considered as interesting and, in the case of pods, cheap sources of value-added phenolic phytochemicals in agreement with literature ${ }^{36,37}$ In particular, the carob pod extracts could be appropriate for use in nutraceutical/pharmaceutical fields when obtained at unripe stage. ${ }^{38}$ The use of carob pod extracts in functional foods, together with the use of the flour in gluten free products could help to counteract the dramatic decline registered over the last century, from 650000tons in 1945 to about 300000 ton in the nineties. ${ }^{39}$ 
As highlighted by the experimental results, pomegranate peels have a great potential as nutraceutical ingredients due to their antioxidant contents that are higher than those of the edible part of fruit. ${ }^{13,40}$ Since the world production of pomegranates is about 3 milliontons and is generally devoted to the juice extraction, pomegranate peels could represent an ideal candidate to the waste valorisation through their conversion into value-added ingredients.

\section{Conclusion}

Phenolics are widespread in vegetable matrices and, sometimes, the most important natural sources are represented by the waste of agro-food industry as in the case of pomegranate peels while the vegetables traditionally considered rich in these phytochemicals are a negligible source also in consideration of the low amount used in food preparation (spices). Although the yields were lower than those of other solvents, water can be considered as extraction solvent due to its low environmental impact. This study suggested that phenolic extracts from pomegranate peels and carobs pods could be considered as alternative antioxidants to those generally used in food processing for two reasons: the considerable phenolic concentrations and the dry matter generally higher than $90 \%$ that allows the storage of the materials before extraction without further dehydration steps. Traditional spice, horse bean, and tomato stem extracts showed low antioxidant contents and low antioxidant activity values. Nevertheless, further studies concerning their bioavailability and metabolism must be performed to explore their suitability as nutraceutical ingredients.

\section{Compliance with ethics requirements}

This article does not contain any studies with human or animal subjects.

\section{Conflicts of interest}

The authors have no conflict of interest to declare.

\section{References}

1. Yasmeen R, Fukugawa NK, Wang TTY. Establishing health benefits of bioactive food components: a basic research scientist's perspective. Curr Opin Biotechnol. 2017;44:109-114.

2. Krzyzanowska J, Czubacka A, Oleszek W. Dietary Phytochemicals and Human Health. In: Giardi MT, Rea G, Berra B, editors. Bio-Farms for Nutraceuticals. MA: Springer; 2010;698:74-98.

3. Lampe JW. Spicing up a vegetarian diet: chemopreventive effects of phytochemicals. Am J Clin Nutr. 2003;78(3 Suppl):579S-583S.

4. Opara EI, Chohan M. Culinary Herbs and Spices: Their Bioactive Properties, the Contribution of Polyphenols and the Challenges in Deducing Their True Health Benefits. Cul Int J Mol Sci. 2014;15(10):19183-19202.

5. Gordon MH. Dietary antioxidants in disease prevention. Nat Prod Rep. 1996;13(4):265-273.

6. NIIR Board of Consultants \& Engineers. The Complete Book on Spices \& Condiments (with Cultivation, Processing \& Uses). 2nd ed. USA: Asia Pacific Business Press Inc; 2006.

7. Taurisano V, Anzelmo G, Poli A, et al. Re-use of agro-industrial waste: recovery of valuable compounds by eco-friendly technique. IJPE 2014;10(4):419-425.

8. De Las Fuentes L, Sanders B, Lorenzo A, Alber S. Awarenet: AgroFood Waste Minimisation and Reduction Network. In: Waldron KW,
Faulds CB, Smith AC, editors. Total Food 2004, exploiting co-productsminimizing waste. Proceedings Volume, Institute of Food Research; 2004. p. 233-244.

9. Laufenberg G, Kunz B, Nystroem M. Transformation of vegetable waste into value added products: (A) the upgrading concept; (B) practical implementations. Biores Technol. 2003;87(2):167-198.

10. Tommonaro G, Poli A, De Rosa S, et al. Tomato Derived Polysaccharides for Biotechnological Applications: Chemical and Biological Approaches. Molecules. 2008;13(6):1384-1398.

11. Gil MI, Tomás-Barberán FA, Hess-Pierce B, et al. Antioxidant capacities, phenolic compounds, carotenoids, and vitamin $\mathrm{C}$ contents of nectarine, peach, and plum cultivars from California. J Agric Food Chem. 2002;50(17):4976-4982.

12. Gorinstein S, Martín-Belloso O, Lojek A,et al. Comparative content of some phytochemicals in Spanish apples, peaches and pears. J Sci Food Agric. 2002;82(10):1166-1170.

13. Li Y, Guo C, Yang J, et al. Evaluation of antioxidant properties of pomegranate peel extract in comparison with pomegranate pulp extract. Food Chem. 2006;96(2):254-260.

14. Baiano A, Bevilacqua L, Terracone C, et al. Single and interactive effects of process variables on antioxidant content and antioxidant activity of vegetable aqueous extracts obtained by conventional and microwaveassisted extractions. J Food Eng. 2014;120:135-145.

15. Gorinstein S, Caspi A, Zemser M, et al. Comparative contents of some fenolics in beer red and white wines. Nutr Res. 2000;20(1):131-139.

16. Re R, Pellegrini N, Proteggente A, et al. Antioxidant activity applying an improved ABTS radical cation decolorization assay. Free Radic Biol Med. 1999;26(9-10):1231-1237.

17. Brand-Williams W, Cuvelier ME, Berset C. Use of a free radical method to evaluate antioxidant activity. LWT-Food Sci Technol. 1995;28(1):2530.

18. Floegel A, Kim DO, Chung SJ, et al. Comparison of ABTS/DPPH assays to measure antioxidant capacity in popular antioxidant-rich US foods. $J$ Food Comp Anal. 2011;24(7):1043-1048.

19. Carlsen MH, Halvorsen BL, Holte K, et al. The total antioxidant content of more than 3100 foods, beverages, spices, herbs and supplements used worldwide. Nutrition J. 2010;9:3.

20. Gunasekar M, Geemon K, Mariwala SJ. Health benefits of bioactive molecules from spices and aromatic plants. $J$ Spices Aromat Crops. 2012;21(2):87-101.

21. Vasanthi HR, Parameswari RP. Indian spices for healthy heart-An overview. Curr Cardiol Rev. 2010;6(4):274-279.

22. Ingvild $\mathrm{P}$, Carlsen $\mathrm{MH}$, Halvorsen BL, et al. Antioxidants in Herbs and Spices-Roles in Oxidative Stress and Redox Signalling. In: Benzie IFF, Wachtel Galor S, editors. 2nd edition. Herbal Medicine: Biomolecular and Clinical Aspects. USA: CRC Press/Taylor \& Francis; 2011.

23. Silva-Beltrán NP, Ruiz-Cruz S, Cira-Chávez LA, et al. Total phenolic, flavonoid, tomatine, and tomatidine contents and antioxidant and antimicrobial activities of extracts of tomato plant. Int $J$ Anal Chem. 2015:284071

24. ISMEA. I numeri della filiera del pomodoro da industria. 2018.

25. Piao XM, Jang EK, Chung JW, et al. Variation in antioxidant activity and polyphenol content in tomato stems and leaves. Plant Breed Biotechnol. 2013;1(4):366-373.

26. Boudjou S, Oomah BD, Zaidi F, et al. Phenolics content and antioxidant and anti-inflammatory activities of legume fractions. Food Chem. 2013;138(2-3):1543-1550. 
27. Boukhanouf S, Louaileche H, Perrin D. Phytochemical content and in vitro antioxidant activity of faba bean (Vicia faba L.) as affected by maturity stage and cooking practice. Int Food Res J. 2016;23(3):954-961.

28. Goli AH, Barzegar M, Sahari NA. Antioxidant activity and total phenolic compounds of pistachio (Pistachia vera) hull extracts. Food Chem. 2005;92:521-525.

29. Erşan S, Güçlü Üstündağ O, Carle R, et al. Identification of phenolic compounds in red and green pistachio (Pistacia vera 1.) hulls (exoand mesocarp) by HPLC-DAD-ESI-(HR)-MS(n). J Agric Food Chem. 2016;64(26):5334-5344.

30. Abbasi S, Vahabzadeh F, Mehranian M. Profiles of phenolics and antioxidant activity of pistachio hulls during solid-state fermentation by Phanerochaete chrysosporium-Involvement of lignin peroxidase and manganese peroxidase. Sci Iran. 2007;14:373-378.

31. Makris DP, Kefalas P. Carob Pods (Ceratonia siliqua L.) as a Source of Polyphenolic Antioxidants. Biotechnol. 2004;42(2):105-108.

32. Kumazawa S, Taniguchi M, Suzuki Y, et al. Antioxidant activity of polyphenols in carob pods. J Agric Food Chem. 2002;50(2):373-377.

33. Ydjedd, Chaalal M, Richard G, et al. Assessment of antioxidant potential of phenolic compounds fractions of Algerian Ceratonia siliqua L. pods during ripening stages. Inte Food Res J. 2017;24:2041-2049.

34. Battle I, Tous J. Carob tree. Ceratonia siliqua L. Promoting the conservation and use of underutilized and neglected crops. 17. Institute of Plan Genetics and Crop Plant Research. Italy: Gatersleben/International Plant Genetic Resources Institute; 1997.
35. Masci A, Coccia A, Lendaro E, et al. Evaluation of different extraction methods from pomegranate whole fruit or peels and the antioxidant and antiproliferative activity of the polyphenolic fraction. Food Chem. 2016;202:59-69.

36. Tsao R, Yu Q, Potter J, et al. Direct and simultaneous analysis of sinigrin and allyl isothiocyanate in mustard samples by high-performance liquid chromatography. J Agric Food Chem . 2002;50(17):4749-4753.

37. Roseiro LB, Tavares CS, Roseiro JC, et al. Antioxidants from aqueous decoction of carob pods biomass (Ceretonia siliqua L.): Optimisation using response surface methodology and phenolic profile by capillary electrophoresis. Ind Crops Prod. 2013;44:119-126.

38. Orak HH, Karamać M, Orak A, et al. Antioxidant potential and phenolic compounds of some widely consumed turkish white bean (Phaseolus vulgaris L.) varieties. Pol J Food Nutr Sci. 2016;66(4):253-260.

39. Garavand F, Madadlou A, Moini S. Determination of phenolic profile and antioxidant activity of pistachio hull using high-performance liquid chromatography-diode array detector-electro-spray ionization-mass spectrometry as affected by ultrasound and microwave. Int J Food Prop. 2017;20(1):19-29.

40. Çam M, İçyer NC. Phenolics of pomegranate peels: extraction optimization by central composite design and alpha glucosidase inhibition potentials. J Food Sci Technol. 2015;52(3):1489-1497. 